\title{
Rede associativa: uma nova proposta de análise para os compostos neoclássicos
}

\section{Association network: a new proposal of analysis for neoclassical compounds}

Neide Higino da Silva

Universidade Federal do Rio de Janeiro, Rio de Janeiro, Rio de Janeiro / Brasil neidehigino@uol.com.br

Carlos Alexandre Victorio Gonçalves

Universidade Federal do Rio de Janeiro, Rio de Janeiro, Rio de Janeiro / Brasil carlexandre@bol.com.br

Resumo: Este trabalho investiga as relações estruturais entre compostos neoclássicos. O objetivo é identificar características que possam estabelecer vínculos entre construções que, em princípio, apresentam-se como díspares em função dos diferentes elementos que as constituem (agrologia, agromoda, autódromo, cachorródromo). No entanto, essas composições apresentam um grau de semelhança relacional que influencia a sua categorização, se analisadas a partir do continuum composiçãoderivação, como proposto por Bauer (2005), Kastovsky (2009), Gonçalves (2011a) e Gonçalves e Andrade (2012). Considerando uma rede de associações estruturais, de acordo com Bybee (2010), é formulado um esquema geral de formação para os compostos neoclássicos.

Palavras chave: compostos neoclássicos; continuum; rede associativa; esquema de formação. 
Abstract: This paper investigates the structural relation between neoclassical compounds. The objective is to identify characteristics that can establish links between constructions that, at first, might appear as disparate, depending on the different elements that constitute them (agrologia, agromoda, autódromo, cachorródromo). However, these compounds exhibit a degree of relational similarity that influences the categorization of these constructions, if analyzed from the continuum composition-derivation, as proposed by Bauer (2005), Kastovsky (2009), Gonçalves (2011a) and Gonçalves and Andrade (2012). Taking into account a network of structural associations according to Bybee (2010), a general scheme is formulated for neoclassicals compounds.

Keywords: neoclassical compounds; continuum; associative network; formation scheme neoclassical words.

Recebido em: 31 de maio de 2016. Aprovado em: 8 de setembro de 2016.

\section{Introdução}

A descrição dos compostos neoclássicos em diferentes línguas (inglês, francês, grego, alemão, português) tem suscitado discussões a respeito da classificação dessas formações como compostos do vernáculo, uma vez que o estatuto dos radicais neoclássicos, formativos que constituem essas palavras complexas, é controverso. Diferentes autores (BAUER, 1998; LÜDELING, 2006; AMIOT; DAL, 2007; RALLI, 2008a, 2008b; PETROPOULOU, 2009; GONÇALVES, 2011b; PANOCOVÁ, 2012, GONÇALVES; ANDRADE, 2012), apresentam, em suas análises, como características convergentes entre os compostos neoclássicos: (1) a dificuldade em definir um estatuto para os constituintes das construções neoclássicas, em função de englobarem elementos etimologicamente comuns, mas que, na atual sincronia das línguas já mencionadas, têm características gramaticais distintas umas das outras; (2) o reconhecimento das diferenças estruturais entre as composições vernaculares e as composições neoclássicas, que possuem, a depender 
da língua, maior ou menor semelhança; (3) essas formações podem combinar-se a elementos nativos; (4) estão passíveis de encurtamento e de ressignificação; e (5) possuem uma vogal intermediária.

Considerando as características comuns, mais especificamente, a vogal fronteiriça entre as bases dessas construções, analisamos, neste texto, a relação entre diferentes formações que recebem na literatura a classificação de compostos neoclássicos.

$\mathrm{Na}$ esteira dos autores referenciados e à luz de Mattoso Camara (1977), Li Ching (1973), Monteiro (1998), Kehdi (1999), Gonçalves (2011b), Caetano (2010), Villalva (1994) e Villalva e Silvestre (2014) e das gramáticas latina e grega, examinamos a vogal fronteiriça entre os compostos neoclássicos, elemento estrutural, que mantém uma rede associativa entre palavras que, em princípio, apresentam-se como distintas (ecofonia, automóvel, agromoda, público-privado, linguodental). Partimos da hipótese de que as vogais fronteiriças, associadas às situações de uso (domínio técnico-científico), seriam um ponto comum entre as diferentes construções, gerando um esquema ou uma construção mais geral, por meio do qual novos dados são criados.

O modelo baseado no uso (LANGACKER, 2008; BYBEE, 2010) é o referencial linguístico que norteia este trabalho, uma vez que as estruturas investigadas são compreendidas como resultado de atividades cognitivas e sociais que se manifestam em mudanças linguísticas.

$\mathrm{O}$ artigo está organizado em cinco seções. Na seção 1, é apresentada a fundamentação teórica adotada na investigação. Na seção 2, é descrito o processo de composição nas línguas clássicas, latim e grego, considerando o papel do segmento vocálico recorrente nessas formações. Na seção 3, são expostas as classificações, na atual sincronia, para a vogal fronteiriça presente entre as bases dos compostos neoclássicos em diferentes línguas. Na seção 4, são analisadas diferentes construções constituídas por radicais neoclássicos no português, a fim de identificar semelhanças e uma possível rede associativa entre elas. Na seção 5, expomos as contribuições deste trabalho.

\subsection{Fundamentação teórica}

Langacker (2008), com ênfase na cognição, concebe a gramática como a organização global do sistema linguístico de natureza simbólica. A linguagem está vinculada à interação social, mas até mesmo a sua função interativa é extremamente dependente de conceptualização. 
A organização global reflete diretamente na função semiológica básica da linguagem, ou seja, permite que significados sejam simbolizados fonologicamente. Para desempenhar essa função, uma língua precisa de, pelo menos, três tipos de estruturas: semântica, fonológica e simbólica. Conjuntos simbólicos podem ser específicos ou esquemáticos. Os primeiros constituem manifestações linguísticas (como palavras, frases e orações). Já os últimos são a extração de características comuns das diversas experiências linguísticas, pelas quais se obtém uma representação de nível mais alto de abstração, denominado, na Gramática das Construções ${ }^{1}$ (doravante GC), de esquemas de construção (LANGACKER, 2008, p. 167). Os esquemas, uma vez estabelecidos como unidade, podem servir como referência para a formação de novas expressões no mesmo padrão.

A construção, na $\mathrm{GC}$, consiste no pareamento entre forma e significado que varia conforme a extensão e a categoria dos constituintes das construções, gerando implicações nas relações internas estabelecidas entre eles. Langacker (2008, p. 15) assevera que as estruturas semânticas são conceptualizações exploradas para fins linguísticos, particularmente como significado das expressões. Sob a rubrica de estruturas fonológicas, o autor (2008, p. 15) inclui não apenas sons, mas também gestos e representações ortográficas. A característica essencial dessas duas estruturas é a de se manifestarem abertamente, sendo, portanto, capazes de cumprir um papel simbólico. Já as estruturas simbólicas não são distintas das estruturas semânticas e fonológicas, mas incorporam-nas.

No tocante à categoria dos constituintes das construções, Bybee (2010, p. 22-23) defende uma rede de associações entre as palavras, ou seja, por meio de um mapeamento, identificam-se semelhanças semânticas e fonéticas compartilhadas por palavras distintas, chegando assim aos constituintes da construção. A autora (2010) apresenta as possíveis redes emergentes das relações morfológicas entre as seguintes palavras: readable $>$ washable $>$ unbelievable $<$ believe $<$ unattractive, unwarranted. ${ }^{2}$

\footnotetext{
${ }^{1}$ Segundo Croft e Cruse (2004, p 257-258), a GC é um modelo teórico não derivacional que compreende o conhecimento gramatical como construções. A diferença central entre as teorias sintáticas componenciais e a gramática das construções está na ligação simbólica entre forma e significado; para as primeiras, a relação é externa, faz-se por meio de regras; para a segunda, é interna.

${ }^{2}$ Legível, lavável, inacreditável, acreditar, desinteressante, injustificadas (tradução nossa).
} 
A identificação de morfemas, por meio da oposição entre palavras, pode lembrar a comutação, técnica de cunho estruturalista baseada "no princípio de que tudo no sistema linguístico é oposição e consiste na substituição, pelo confronto, de uma forma por outra". (MONTEIRO, 1986, p. 49). No entanto, nessa perspectiva, são considerados apenas aspectos sincrônicos e todos os elementos analisados devem possuir significados. Portanto, -ada, em manada (exemplo de MONTEIRO, 1986, p. 53), não deve ser analisado, uma vez que a forma resultante, após a retirada do sufixo, não é reconhecida sincronicamente. De acordo com Bybee (2010, p. 23), a vantagem da rede de associações advém da não exigência de uma palavra ser exaustivamente analisada em morfemas.

Croft e Cruse (2004, p. 292) afirmam que cada vez que uma construção é usada, ativa um nó ou padrão de nó na mente. A frequência de ativação afeta o armazenamento da informação, levando, finalmente, ao armazenamento da unidade gramatical convencional. Segundo Langacker (2008, p. 17), a estabilidade dessas unidades de construção é garantida pelos eventos de uso, ou seja, uma situação real de comunicação. A independência de armazenagem, ou seja, o entrincheiramento, é determinado pela frequência de ocorrência de uma construção (frequência token). Segundo Bybee (2010), rotinas cognitivas entrincheiradas são formas repetidas com um alto grau de frequência de uso, sendo, por isso, armazenadas independentemente na memória. Esse é o caso da formação neoclássica locomoção, que contém o mesmo radical que local (do latim locus, "lugar"), mas hoje é entrincheirada e, certamente, interpretada holisticamente.

Para Bybee (2010, p. 94-95) a produtividade, isto é, a capacidade de aplicar a estrutura existente a novos enunciados, está diretamente relacionada à frequência type, ou seja, ao número de diferentes construções que instanciam ${ }^{3}$ um esquema: quanto mais alta a frequência type, maior a produtividade. Já a alta frequência token (o uso recorrente de uma mesma construção) contribui menos para a produtividade, uma vez

3 Instanciação é uma relação sustentada pelo amplo inventário altamente estruturado de conjunto simbólico conhecido pelo falante que se manifesta no uso da linguagem (cf. LANGACKER, 2008, p. 17). 
que torna a construção autônoma e com menos analisabilidade. ${ }^{4}$ Quando uma construção atinge uma alta frequência token, é processada sem ativar os outros exemplares da construção e começa a perder analisabilidade e composicionalidade. ${ }^{5}$ Assim, construções constituídas principalmente por membros de alta frequência ou expressões estereotipadas tenderão a não ser produtivas. Portanto, a alta frequência token diminui a produtividade na morfologia e também na morfossintaxe, ao atingir certo nível de autonomia. Tal como em caleidoscópio, em que a identificação da estrutura morfológica é parcial, uma vez que-scópio é isolável por meio da formação de uma rede associativa com outras palavras, a exemplo de telescópio e endoscópio; no entanto, caleido- perdeu a analisabilidade. A composicionalidade, nesse dado, também está comprometida, pois o significado da composição não é soma dos significados das partes, pois o sentido do radical grego cali ("belo") é opaco.

Bybee (2010, p. 35) afirma que a esquematicidade, ou seja, um esquema preenchido por constituintes, tende a tornar o esquema menos produtivo. A autora ratifica sua hipótese argumentando que esquemas abertos (menos preenchidos por constituintes) são mais produtivos em função da alta frequência type, uma vez que o mecanismo por trás da produtividade é a analogia entre os itens específicos. Um esquema aberto com alta frequência type será mais susceptível de ser utilizado em novos enunciados do que os que têm baixa frequência. Logo, a relação entre expressões convencionais e novas formações, segundo Bybee (2010, p. 57), pode ocorrer via analogia. Um exemplo desse tipo de relação envolvendo a composição neoclássica é a recente formação ortorexia ("distúrbio alimentar caracterizado pelo consumo de produtos sem química"), provavelmente, cunhada a partir de anorexia ("redução ou perda de apetite, que resulta em uma extrema magreza do indivíduo").

\footnotetext{
${ }^{4}$ Segundo Bybee (2010), a analisabilidade é o reconhecimento da contribuição de cada componente para o significado composicional. Esse conceito envolve o conhecimento do falante sobre as palavras e os morfemas que a compõem, bem como o da sua estrutura morfossintática, ou seja, reconhecimento de sua estrutura morfológica. De acordo com a autora (2010), a analisabilidade também é gradiente, uma vez que as partes de uma construção podem ser total ou parcialmente identificadas

${ }^{5}$ Composicionalidade, de acordo com Bybee (2010), é uma medida semântica referente ao grau de previsibilidade do significado do todo a partir do significado das partes.
} 
A autora (2010) utiliza o conceito com sentido mais abrangente: processo pelo qual um falante cria um item novo em uma construção. Bybee (2010) acrescenta que a especificidade das construções e a maneira como os novos dados são construídos, por meio da experiência com a linguagem, gera um gradiente, pois a probabilidade e a aceitabilidade de um item novo ocorrem com base no grau de semelhança com os usos anteriores da construção. Portanto, analogia não é apenas um mecanismo de regularização morfológica, mas também o principal mecanismo de criatividade morfossintática e de mudança fonológica, embora esta aconteça em menor escala. Desse modo, concebe a analogia como um processamento de domínico geral, ou seja, uma nova forma é criada pela evocação de uma construção mais geral, e não apenas pela comparação entre elementos individuais.

Por último, descreve que os elementos envolvidos devem ser da mesma natureza, havendo entre eles semelhanças semânticas ou fonológicas. Bybee (2010, p. 102), trazendo à baila a semelhança existente entre as construções, defende que questões tanto de ordem sincrônica quanto de ordem diacrônica podem contribuir para isso. No primeiro caso, por meio da analogia entre exemplares existentes (construção advinda de um conjunto de tokens que são igualmente categorizados pelo falante); no segundo caso, mediante construções desenvolvidas fora da estrutura existente ou construções já existentes que transmitem, por herança, suas propriedades para as novas ao longo do tempo. A mudança linguística não é apenas um fenômeno periférico que pode ser anexado a uma teoria sincrônica; sincronia e diacronia têm de ser vistas como um todo integrado.

A autora (2010, p. 119) conclui que, embora seja certamente necessário entender os papéis distintos de sincronia e diacronia quanto à descrição e à teoria, importa também ter em mente que a linguagem é um objeto cultural convencional que tem evoluído ao longo do tempo e continua a evoluir. A teoria linguística não é completa se não abraçar a contribuição de mudança linguística para a compreensão da estrutura da linguagem.

Na próxima seção, como base nas gramáticas gregas e latinas, será analisado o processo de composição. 


\section{Formação dos compostos segundo as gramáticas latina e grega}

\subsection{Gramática latina}

De acordo com Allen e Greenough (1903, p. 60), palavras compostas são aquelas cujo tronco é constituído de dois ou mais radicais simples. Os autores descrevem, em seguida, o processo de composição no latim: a vogal final do radical do primeiro membro da composição, diante de outra vogal ou de uma consoante, geralmente, desaparece e toma a forma de $i$, recebendo apenas o segundo membro flexão. Nos casos em que $o$ - e $a$ - são as vogais finais dos radicais, essas são suprimidas, e aparece $i$ - no seu lugar, tal como em āli-pěs (a partir de $\bar{a} l a$, raiz $\bar{a} l \bar{a}$ ); portanto, $i$ - é a terminação comum dos radicais em compostos e é, frequentemente, adicionada aos radicais que não a têm, como, flōri-comus ("corroa de flores") (a partir flōs, flōr-is ("flor") e coma ("cabelo")). Apenas radicais substantivos podem ser assim compostos.

Allen e Greenough (1903, p. 13) ressaltam, ainda, que as formas classificadas de raízes nunca existiram em latim, mas remetem a formas utilizadas antes de o latim constituir-se como língua autônoma. Monteil (1992, p. 177) assevera que, ao traçar um paralelo entre a flexão temática no indo-europeu e no latim, a formação dos temas em latim, assim como em grego, resulta de uma tematização secundária, uma vez que no indo-europeu a flexão temática não possuía nomes raízes, ${ }^{6}$ nem temas primários, mas temas secundários, com sufixação. De acordo com o proposto, a terminação $-r o$, presente em ager $=\alpha \gamma \rho o ́ \varsigma$, uesper $=\dot{\varepsilon} \sigma \pi \varepsilon \rho \circ$,

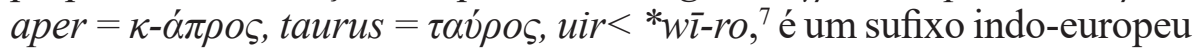
remanescente. Allen e Greenough (1903) e Monteil (1992) sugerem que os processos morfológicos no latim se davam a partir de radicais, ou seja, uma forma primária acrescida de um elemento morfológico.

Bennett (1913, p. 115), em A latin grammar, diferentemente de Allen e Greengough (1903), afirma que os compostos em latim são formados pela união de palavras simples. O segundo membro contém o significado essencial da composição e o primeiro funciona como um modificador. No processo de composição, as vogais sofrem mudanças

\footnotetext{
${ }^{6}$ Monteil (1992) define raiz como um esquema, reconstruído da estrutura indo-europeia, que corresponde ao elemento significante da palavra.

${ }^{7}$ Forma hipotética indo-europeia.
} 
frequentes. Essas podem ocorrer no segundo membro da composição ou no primeiro.

Bennett (1913, p. 115) assevera que, no primeiro constituinte, o $\breve{l}$ aparece, frequentemente, como vogal temática desse elemento e, algumas vezes, essa vogal ocupa a posição do ŏ ou do $\breve{a}$. Entretanto, em algumas situações o $\breve{1}$ pode ser completamente descartado. Quando o primeiro vocábulo termina por consoante, faz-se uma epêntese utilizando a vogal. $\mathrm{O}$ autor cita os seguintes exemplos, sem, contudo, detalhar o processo de composição: signifer ("porta-estandarte"); tubicen ("trombeteiro"); magnanimus ("magnânimo, nobre"); matricida ("matricida”). Na próxima subseção, será descrito o processo de composição pela gramática grega.

\subsection{Gramática grega}

Horta (1970, p. 391) afirma que a maior parte do léxico grego é formada por composição (radical formado de dois ou mais elementos) ou por derivação (formado por sufixos). Segundo a autora (1970, p. 392), palavras compostas são facilmente formadas no grego. ${ }^{8} \mathrm{O}$ primeiro elemento da composição pode ser um prefixo ('́ $\xi$ ("fora de") +

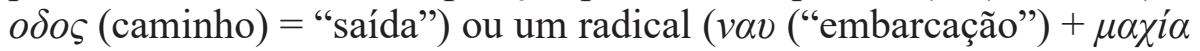
("batalha") = "batalha naval"), sendo o segundo elemento sempre um radical. Horta (1970) afirma que as bases dos compostos ora combinamse diretamente, ora combinam-se por intermédio de uma vogal de ligação; no entanto, a autora não detalha quais são essas possíveis vogais fronteiriças.

Segundo Goodwin (1900, p. 191), em sua Greek Grammar, na composição de palavras, são observadas: a) a primeira parte da composição, b) a segunda parte e c) o significado do todo. Quando a primeira parte dos compostos é um substantivo ou um adjetivo, somente seu radical aparece na composição. O autor não cita exemplos.

No que se refere a alterações internas da composição, o autor (1900, p. 191) afirma que diante de uma consoante, o radical da primeira declinação geralmente muda a vogal $\bar{\alpha}$ final, passando a $o: \theta \alpha \lambda \alpha \sigma \sigma \bar{\alpha}$

\footnotetext{
${ }^{8}$ Optamos por transcrever os dados na língua de origem, utilizando os símbolos empregados em grego, para (a) preservar as fontes citadas e (b) identificar, com mais clareza, o processo de composição nessa língua. Como sempre apresentamos o significado dos compostos, julgamos não ser necessária a transcrição fonética dos dados.
} 


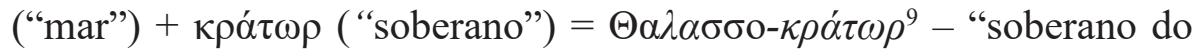
mar"; o radical de segunda declinação mantém o -o: $\chi \rho \rho o$ ("coro, dança") $+\delta l \delta \dot{\alpha} \sigma \kappa \alpha \lambda o \varsigma$ ("instrutor") = $\chi \sigma \rho o-\delta l \delta \dot{\alpha} \sigma \kappa \alpha \lambda o \varsigma$ - "instrutor de coro, de dança"; e o radical de terceira é acrescido de -o: ( $\pi \alpha l \delta$ ("criança") + $\tau \rho i \beta \eta \varsigma$ ("atrito") = $\pi \alpha l \delta o-\tau \rho i \beta \eta \varsigma$ - "treinador físico, aquele que treina crianças". Diante de uma vogal, os radicais de primeira e de segunda declinações perdem suas vogais finais $\bar{\alpha} \mathrm{e} o$, respectivamente, como em $\kappa \varepsilon \phi \alpha \lambda \bar{\alpha}$ ("cabeça") $+\alpha \lambda \gamma \eta$ ' ("dor") = $\kappa \varepsilon \phi \alpha \lambda-\alpha \lambda \gamma \eta \dot{ }$ - "dor de cabeça";

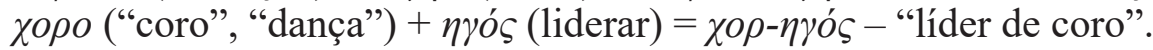

Há, no entanto, ainda de acordo com Goodwin (1900) situações

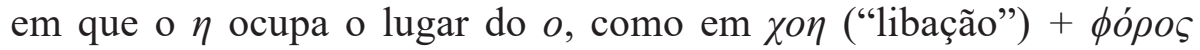

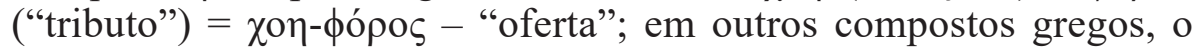
substantivo aparece em um dos seus casos, como se fosse uma palavra

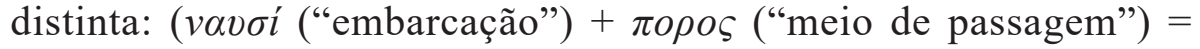

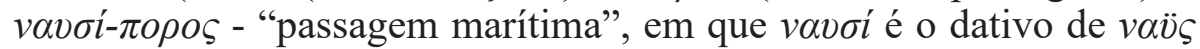
("embarcação").

Já nas questões que tratam do segundo elemento, quando esse inicia-se por $\alpha$, $\varepsilon$, ou $o$ (a menos que essas vogais sejam longas pela posição), é muito frequente serem alongadas passando a $\eta$ ou $\omega$, a exemplo de $\Sigma \tau \rho \alpha \tau$ ("exército") + $\eta \gamma o ́ \varsigma$ ("liderar") $=\Sigma \tau \rho \alpha \tau-\eta \gamma o ́ \varsigma-$ "general"; $\kappa \alpha \tau \dot{\alpha}$ ("movimento de cima para baixo") + $\varepsilon \rho \dot{\phi} \phi \omega$ ("cobrir com telhado") $=\kappa \alpha \tau-\eta \rho \varepsilon \phi \eta ́ \varsigma$ - "coberto por algo que está por cima" e

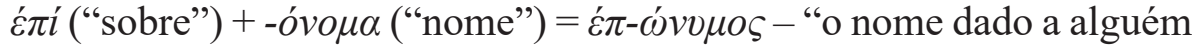
ou a alguma coisa".

Considerando as formações em uma perspectiva etimológica e as descrições das gramáticas latinas e grega, as vogais presentes nas composições latinas e gregas, -i- e -o-, respectivamente, são marcadores de composições passíveis, nas suas línguas de origem, de modificação. Na próxima seção, são expostas análises de Ralli (2008a, 2008b), Petropoulou (2009), Lüdeling (2006), Bauer (1998), Amiot e Dal (2007) e Kastovsky (2009), a fim de reunir os pareceres de diferentes autores, sobre um possível estatuto da vogal fronteiriça em diferentes línguas.

\footnotetext{
${ }^{9}$ Mantivemos o hífen das palavras compostas, conforme apresentadas por Goodwin (1900).
} 


\section{Descrição do segmento vocálico em diferentes línguas}

Ralli (2008b), pautada numa abordagem gerativista, defende a existência de um marcador de compostos em grego moderno e em outras línguas tipologicamente diferentes. Propõe que a presença de tal marcador se relaciona com um parâmetro de flexão paradigmática explicitamente realizada e que o seu caráter sistemático ou não sistemático depende da categoria dos constituintes, radical ou palavra, que estão envolvidos na formação do composto. Mostra também que, com relação à origem, o marcador pode ser resíduo sincrônico de uma epêntese fonológica ou o produto da evolução de outros elementos funcionais ou lexicais que se tenham submetido ao processo de morfologização.

Compreendendo composição como um processo de formação de palavras que caracteriza as línguas de vários tipos e várias famílias, a autora define o mecanismo como uma associação entre palavras ou radicais, dependendo da morfologia da língua em particular, e cita o inglês como exemplo de língua em que composição ocorre entre palavras, e o grego como exemplo de língua em que a composição se baseia em radicais.

Ralli (2008b) afirma que, em alguns idiomas, os compostos apresentam um segmento semanticamente vazio entre o primeiro e o segundo componentes (p. exemplo, a palavra grega kukl-o-spito = "casa de boneca"). Segundo a autora, em compostos de outros idiomas, este segmento não vem à superfície, a exemplo da palavra inglesa appletree ("macieira"). Ralli (2008b) faz referência às diferentes denominações que o segmento recebe na literatura: elemento de ligação, interfixo ou, mais raramente, confixo.

Ralli (2008b) não discute, todavia, o estatuto do segmento intermediário presente nos compostos neoclássicos, fazendo apenas menção à origem dos radicais-base dessas formações, grego antigo e latim, uma vez que a pesquisa se restringe a analisar os compostos vernáculos produtivos do grego moderno. Contudo, Ralli (2008a) salienta que as formações neoclássicas em grego moderno se diferenciam das composições produtivas regulares apenas no que diz respeito à natureza dos seus constituintes, e afirma que as propriedades estruturais da base são as mesmas, entre elas, o marcador de compostos -o-. Logo, o -o- é um marcador tanto nas composições do grego moderno quanto nas formações neoclássicas dessa língua. 
Petropoulou (2009) elenca como uma das características importantes dos neoclássicos prototípicos, tendo como base de análise o inglês e o grego moderno, a existência de um elemento de ligação (-oou -i-) entre os constituintes da composição, orginalmente uma vogal temática que passou a marcador composicional nas línguas de origem, grego ou latim.

Lüdeling (2006) lança mão de alguns exemplos de diferentes línguas europeias, mas propõe uma análise mais geral dessas formações. A autora faz referência ao elemento de ligação que aparece nessas palavras complexas, indicando que -o-, geralmente, exerce essa função, porém há possibilidade de outra vogal exercer o mesmo papel. Lüdeling (2006) questiona o vínculo morfológico desse elemento, se ao primeiro ou ao segundo constituinte da composição, levantando a hipótese de a vogal ser requerida por um dos constituintes.

Bauer (1998) descreve a dificuldade em identificar o estatuto da vogal -o- que comumente aparece entre os constituintes dos compostos neoclássicos em inglês. $\mathrm{O}$ autor assevera que, no grego clássico, o -o- era uma vogal temática, mas tornou-se, gradativamente, em um elemento de ligação da composição, desempenhando esse papel no grego moderno.

Bauer (1998) arrola quatro possiblidades de interpretação para essa vogal nas novas formações: (a) como um elemento de ligação entre formas encurtadas, como em phot e graph, embora diga que é incomum a forma phot realizar-se em inglês (photic, photopsy); (b) como parte do primeiro elemento, quando este elemento estiver ligado a lexemas (photoluminescence); (c) como parte do segundo elemento, quando o segundo elemento é ligado a lexemas (Addressograph ${ }^{\circledR},{ }^{10}$ phraseograph); (d) como pertencente, simultaneamente, aos componentes inicial e final (como em (b) e (c)), e a sequência -oo- é morfofonemicamente reduzida a um único -o-.

Segundo Bauer (1998), uma das diferenças entre os compostos neoclássicos e outros padrões de formação de palavras em inglês é que neoclássicos não são nativos. O elemento de ligação -o- é visto, em última análise, como um segmento próprio da palavra em grego, e não de uma

\footnotetext{
10 "Marca registrada de uma empresa norte-americana que fazia máquinas para imprimir nomes e endereços em jornais, etiquetas de endereçamento, envelopes, cartas, e outros itens".

(http://www.earlyofficemuseum.com/mail_machines.htm)
} 
formação de palavras em inglês. Uma forma como hamburgerology é, inicialmente, um composto em inglês, e, finalmente, um composto neoclássico. Em outras palavras, há uma relação entre a origem grega dos compostos neoclássicos e a anglicidade dos compostos nativos. Muitos outros idiomas distinguem entre os padrões de formação de palavras nativas e estrangeiras. De acordo com Bauer (1998), em holandês, alemão, checo e russo, as bases nativas são concatenadas a afixos nativos e as bases estrangeiras a afixos estrangeiros, mais do que se observa em inglês. Por exemplo, uma forma como Sterbation pode ser totalmente agramatical em alemão, mas Starvation ("fome") é uma palavra real em inglês (embora incomum justamente devido à mistura de elementos nativos e estrangeiros). Em vietnamita, há compostos nativos e compostos estrangeiros (emprestados do chinês), que diferem em termos de modificador e elemento-cabeça. ${ }^{11}$

Entre as características arroladas por Amiot e Dal (2007) para identificação de formas combinatórias clássicas, está a presença de um vogal de ligação, -o- ou -i-. Todavia, diferentemente dos demais autores, Amiot e Dal (2007) chamam a atenção para o ambiente fonológico em que aparecem: contexto fonológico / $\ldots \mathrm{C}_{\mathrm{f}} \mathrm{C}_{\mathrm{i}} \ldots$ / onde $\mathrm{C}$ e $\mathrm{C}$ são consoantes em posição final do primeiro constituinte e posição inicial do segundo componente, respectivamente. De acordo com essa descrição, a vogal -o-, presente entre as bases de agroexportação, por exemplo, não seria um elemento de ligação, pois o constituinte à direita se inicia com a vogal, -e, e não com uma consoante. Segundo as autoras, a presença do -o- ou do -i- está relacionada, nessa ordem, à origem grega ou latina das formas. Outro aspecto salientado é a presença do -o- em formas combinatórias não neoclássicas, tal como em afro-cubain ("afro-cubano").

Kastovsky (2009), examinando as formações neoclássicas no inglês, rechaça a classificação forma combinatória, proposta pela literatura, e expõe diferentes motivos para tal posicionamento, entre os quais o estatuto da vogal intermediária entre os constituintes dessa formação. As formas combinatórias terminariam na vogal -o- ou -i-; contudo, diferentes prefixos exibem essa terminação, entre os citados pelo autor: anti-, epi-, pro-, co-. Assim como Bauer (1998) e Lüdeling

\footnotetext{
${ }^{11}$ Nespor; Vogel (1986) defendem que, entre os constituintes de um sintagma fonológico, há uma cabeça lexical, início de um constituinte. Segundo Callou e Serra (2012, p. 49), cabeça lexical são núcleos de sintagmas sintáticos cuja natureza é lexical e não funcional.
} 
(2006), Kastovsky (2009) indaga a relação morfológica da vogal, se esse segmento pertenceria ao elemento da direita ou ao da esquerda, ou seria apenas uma vogal de ligação. $\mathrm{O}$ autor também aborda o aspecto histórico dessas formações e, consequentemente, desse segmento, ao qual denomina de formativo de radical ${ }^{12}$ do primeiro membro - classificação que recorda os apontamentos, na seção 2.1, de Allen e Greenough (1903) e de Monteil (1992) sobre a formação dos radicais no latim.

Kastovsky (2009) esclarece que radicais gregos, latinos e neolatinos passaram por mudanças. Afirma que o grego e o latim, como todas as línguas indo-europeias, foram, originalmente, baseadas em uma estrutura morfológica tri-partida, raiz + formativo de radical + flexão. $\mathrm{Na}$ composição, a raiz, como primeiro elemento de um composto, foi seguida por um "formativo de radical", como em agr-o-nomia, mas, nas fases posteriores das línguas indo-europeias, foi igualmente seguida por uma vogal de ligação que remonta a uma desinência, como em agr-i-culture. O autor assinala que este último tipo de formação resultou de expressões lexicalizadas envolvendo o caso de marcação do primeiro membro, que serviu de base analógica para formações paralelas, um fenômeno que pode ser observado também em outros ramos do indo-europeu, como as línguas germânicas.

No decorrer do tempo, no entanto, o chamado formativo de radical, e as terminações flexionais originais tornaram-se opacas, mais no latim do que no grego, e esses elementos morfológicos, que já não podem ser identificados com qualquer material flexional, passam a ser reinterpretados como elementos de ligação. Segundo Kastovsky (2009), esses segmentos perderam sua função. O mesmo ocorreu com terminações de caso dos compostos no alemão; contudo, surgem em formações que não são gramaticalmente justificadas. O autor sugere que a presença de um elemento de ligação poderia ser acionada pelo primeiro ou segundo elemento, com base em alguma analogia histórica, e não como um elemento de ligação fazendo parte de um dos constituintes.

Para efeitos de análise, Kastovsky (2009) toma o formativo -logy, presente em anthrop-o-logy, cosm-o-logy, bio-logy, geo-logy, no qual o -o-, por questões históricas, pertence ao constituinte da esquerda. Já em kremlin-o-logy, hamburger-o-logy, life-o-logy, a forma depreendida parece ser -ology. $\mathrm{O}$ autor enumera as seguintes possibilidades de

\footnotetext{
${ }^{12}$ Termo original utilizado pelo autor: stem-formative (cf. Kastovsky, 2009, p. 6)
} 
interpretação para a vogal -o-: a) o sufixo teria adotado a forma -ology; b) -ology seria um alomorfe morfologicamente condicionado de -logy; e c) o sufixo desencadearia a inserção de um elemento de ligação, que não pertenceria a nenhum dos constituintes. Kastovsky (2009) considera a última proposta mais plausível e assinala que os compostos do inglês admitem elemento (s) de ligação, como em officer's mess ("praça d'armas"), driver's license ("carteira de motorista").

No que se refere às formações constituídas de elementos clássicos e elementos vernáculos, tais como filmo- (-graphy), kisso- (-gram), Kastovsky (2009) defende que o-o- entre os constituintes é um elemento de ligação, por analogia às formações clássicas; portanto, não estaria ligado nem ao formativo da direita, nem ao da esquerda. Todavia, sugere que formas como - gram e -logy acionam a vogal, caso essa não seja parte integrante do primeiro elemento.

As hipóteses apresentadas pelos autores mencionados, a partir do exame do inglês, grego e francês, entre observações de outras línguas europeias, indicam que as formações neoclássicas, nessas línguas, possuem como característica um segmento intermediário, geralmente, -o- ou -i-, embora outras vogais possam aparecer nessa posição. Nas formações em que se combinam elementos clássicos e vernáculos, a vogal -o- tende a aparecer.

A próxima seção trata de possíveis classificações no português para as vogais fronteiriças. Para tal, são expostos os argumentos de Mattoso Camara (1977), Li Ching (1973), Monteiro (1998) e Kehdi (1999).

\subsection{Segmento Vocálico: possíveis interpretações para o português}

Li Ching (1973) afirma que o avanço científico trouxe ao uso uma série de elementos, em sua maioria, de origem grega, aos quais o autor denominou pseudoprefixos e cita alguns deles: "aéro-, foto-, geo-, micro-, mono-, rádio-, tele-". O autor chama atenção para uso dessas formas: "não é naturalmente português, mas um fenómeno internacional que ocorre em todas as línguas europeias". Li Ching (1973, p. 213) destaca "o terminus -o-, que é o eixo mais importante nesta série, é uma espécie de infixo da composição que se encontrou há muito tempo, sem dúvida nenhuma, nas formações adjectivas (cf. luso-brasileiro, luso-espanhol, etc.)". 
No que se refere às vogais -o- e -i- intermediárias, nos compostos neoclássicos, Monteiro (1998), ao definir interfixo como "elemento que une uma raiz a um sufixo ou dois radicais de um composto", cita a palavra filósofo e o -ó- entre as duas bases como interfixo, mas, na seção 3.3, em que trata especificamente dos interfixos, o autor não aborda o assunto e comenta apenas "que não devem ser considerados como interfixos os segmentos presentes em decalques ou em termos de origem latina que não produzem mais palavras novas". (MONTEIRO, 1998, p. 65)

Kehdi (1999, p. 191) descreve e analisa diferentes pesquisas sobre infixo e critica a proposta de Li Ching (1973, p. 213), pois a vogal -o- posiciona-se entre radicais e não no interior de um radical, como os infixos. Kehdi (1999, p. 191) ressalta o seguinte: “O verdadeiro caráter da vogal terminal do primeiro elemento do composto é muito mais sufixal [diferentemente do que afirma Li Ching], sobretudo levando-se em conta a produtividade desse tipo de formação e a freqüente redução do composto ao seu primeiro elemento."

Para Mattoso Camara (1977), a categoria infixo inexiste em português, assim como para Kehdi (1999). Este, fundamentado na definição de infixo como "morfema que se introduz no radical" (KEHDI, 1999, p. 191), rechaça a possiblidade de a vogal -o-, presente no final do primeiro elemento dos compostos neoclássicos, ser um infixo. Kehdi (1999), tendo em vista a produtividade dessas formações e o truncamento, que reduz os compostos ao primeiro constituinte, identifica características sufixais na vogal.

Li Ching (1973) não define infixo. O autor defende a existência de infixos nas formações neoclássicas e traça um paralelo com o comportamento de alguns adjetivos compostos, tais como luso-brasileiro e luso-espanhol (exemplos do autor). Diante do exposto, a indagação é a seguinte: se o -o- e -i- fossem infixos, como sugere Li Ching, e, consequentemente, um elemento mórfico, qual seria o seu significado?

Monteiro (1998) afirma que esses segmentos, presentes em formas latinas, não são considerados interfixos, em função de não serem produtivos. Infere-se que a produtividade é o critério responsável pela classificação; logo, sendo produtivo, o segmento pode ser categorizado como interfixo. Contudo, as observações de Monteiro (1998) não incluem as formas de origem grega, pois ele menciona apenas as latinas.

$\mathrm{Na}$ seção seguinte, destacam-se as análises, de Villalva (1994), Villalva e Silvestre (2014), Caetano (2010) e Gonçalves (2011b), sobre o comportamento dessas vogais no português. Os autores apresentam posições distintas a respeito de um possível marcador composicional na língua. 


\subsection{Um marcador composicional para o português}

\section{Villalva (1994) classifica os compostos neoclássicos como composições morfológicas.}

De acordo com a autora, estas são estruturas resultantes de um processo de concatenação de radicais, simples ou complexos, que se comportam como formas livres na língua, ou não, por intermédio de uma vogal de ligação, a exemplo de raticida e luso-brasileiro (citados pela autora). Nessas construções, a vogal intermediária entre as bases é obrigatória, desempenha o papel de especificador da base à esquerda e funciona como elemento de ligação. Segundo Villalva (1994), Villalva e Silvestre (2014), esse segmento intermediário não está vinculado nem à base da direita, nem à da esquerda, sendo, portanto, autônomo, ocorrendo apenas à direita dos radicais que não estão em posição final.

Outro fator para o qual os autores $(1994,2014)$ chamam a atenção é o comportamento fonético da vogal de ligação: essas não sofrem alteamento, muito embora o ambiente fonético proporcione o alçamento da vogal.

Villalva (1994) confere à vogal de ligação, elemento que não possui um caráter bem definido em português, o papel de especificador e, embora defenda a autonomia do segmento na construção, afirma que o vogal está ligada à base da direita. No entanto, Villalva e Silvestre (2014) apresentam o segmento como um marcador de fronteira, portanto, não vinculado a nenhuma das bases, como demonstrado em cardi-o-vascular e taqui-cardi-a.

De acordo com os autores (2014), as vogais -i- e -o-, presentes entre as bases da construção, instanciam-se de acordo com a natureza etimológica do elemento à direita, se de origem latina ou grega, respectivamente. Outro aspecto que influencia a realização das vogais é a relação sintática entre os elementos da composição, se forem formados por coordenação, segundo Villalva e Silvestre (2014), a vogal de ligação será sempre - o -; se forem formados por subordinação, a vogal será -i-. No entanto, os autores ressaltam que a vogal default é o-o-.

Caetano (2010) assume que os compostos do português, em que o primeiro elemento da composição termina nas vogais -o- ou -i-, tais como médico-cirúrgico e novilatino (exemplos da autora), possuem um marcador de fronteira, entre um e outro radical, semelhantemente aos compostos com radicais neoclássicos. Caetano (2010) afirma que, aparentemente, não há diferenças entre a) construções resultantes de 
dois elementos neoclássicos; b) dois elementos vernáculos e c) aquelas em que o primeiro elemento vernáculo é resultante de um truncamento terminando em -o e o segundo, um elemento vernáculo. A autora cita como exemplo as palavras turbo-diesel e turbo-prof, em que o primeiro elemento é oriundo do truncamento de turbocompreensor.

Gonçalves (2011b) afirma que não há, nas composições de base livre em português, marcador de compostos. O autor ressalta que em palavras encurtadas em que o primeiro elemento é de origem grega, a vogal -o- mantém-se no truncamento, como em foto de fotografia e pólio de poliomielite. Gonçalves (2011b) enumera também exemplos de formações híbridas, constituídas de elementos clássicos e vernáculos em que a vogal -o- aparece como um segmento intermediário entre as bases, musicolatria, achologia, oviniologia. O autor destaca que os exemplos sugerem que a vogal não é constituinte fonológico da primeira base.

Além dos casos acima, Gonçalves (2011b) descreve o comportamento sintático de algumas construções: a) nos compostos coordenativos formadores de adjetivos, a primeira palavra apresenta a vogal -o- e a mantém, independe da variação que possa ocorrer com a segunda palavra: aspectos léxico-gramaticais, ações médicohospitalares, metas político-partidárias (exemplos do autor). Essa mesma vogal também é encontrada em compostos determinativos de cabeça à direita, radiomania, beatlomania, sonoterapia, musicoterapia.

No primeiro conjunto de exemplos elencados pelo autor, as bases à esquerda são formas livres que possuem o -o como vogal temática na sua constituição, o que pode comprometer a análise, embora a manutenção da vogal sobreponha-se à concordância entre os componentes coordenativos. Já no segundo conjunto de exemplos, as bases à direita são elementos de origem grega, -mania, -terapia, que conferem à composição um caráter neoclássico e justificaria o acionamento da vogal -o-.

$\mathrm{O}$ autor (2011b) destaca também dois comportamentos fonológicos distintos: a) em que a vogal, mesmo em posição postônica pode não se neutralizar e o todo realizar-se em duas palavras prosódicas, já que a base à esquerda mantém o seu acento: music [o]terapia, bronc [o] embolia (exemplos do autor); b) nas formações em que o segundo elemento é "-metro", "-dromo", "-latra", "-logo" e "-grafo", a vogal de fronteira é tônica e a pretônica neutraliza-se, mas tende a se realizar como aberta, em função da harmonização vocálica. Entre os exemplos citados pelo autor, destacam-se $f[o]$ tógrafo e $l[e]$ prólogo. Em função do exposto, 
o autor afasta a classificação de vogal de ligação para esse segmento intermediário, uma vez que vogais de ligação não portam acento; outro argumento é a realização de diferentes vogais nessa posição, a exemplo de análogo, epílogo, homólogo. (grifo nosso).

Segundo Gonçalves (2011b), as pesquisas de Rondinini (2004) e Rondinini e Gonçalves (2006) indicam que as vogais anteriores a -logo e -grafo foram assumidas como parte do formativo, demonstrando uma transição da composição para a derivação, passando a -ólogo e -ógrafo, respectivamente. Pires (2014) adota a mesma posição em relação à -dromo, pois, segundo o autor (2014), nas novas formações, o elemento à direita assume características de sufixo, passando a -ódromo, o que justifica a presença de uma consoante de ligação em paizódromo ("ginásio que se destina ao encontro entre pais e filhos") e gayzódromo ("local que seria destinado para a realização de ações afirmativas do movimento LGBT"), citados pelo autor (2014).

Portanto, para Villalva e Silvestre (2014), as vogais são elementos de ligação, presentes nos compostos morfológicos como marcador de fronteira entre os radicais. A alternância dos segmentos -o- e-i-, segundo os autores, está condicionada pela relação sintática entre as bases e a natureza etimológica dos constituintes. Já para Caetano (2010), as vogais são marcadores composicionais, independentemente, dos elementos formadores da composição, enquanto Gonçalves (2011b) assume a posição consensual de que não há marcadores de compostos de base livre em português.

\section{Análises de dados: um panorama sobre as diferentes construções neoclássicas do português}

As formações neoclássicas introduzidas em diferentes línguas são fruto da retomada das tradições greco-latinas, no Renascimento, e do Desenvolvimento Científico, no séc. XIX, que fez uso dessas línguas como referência para a criação de palavras relacionadas às novas descobertas. Contudo, como observa Lüdeling (2006, p. 580), a noção de 'neoclássico' não é simplesmente uma noção etimológica. Em primeiro lugar, não se pode esperar que os falantes tenham conhecimento etimológico. Além disso, muitas vezes é difícil determinar a origem de um elemento morfológico porque muitos elementos entram para uma língua através de outras. 
Embora muitos compostos greco-latinos tenham sido formados em outras línguas e tenham chegado ao português via empréstimo indireto, essas composições são analisáveis por constituírem-se de radicais gregos e latinos que já foram incorporados pela língua, a exemplo de -cultura, -metro, -grafia ou por serem doublet, ${ }^{13}$ tais como herb-e erva, pisci- e peixe.

Viaro (2014, p. 270) afirma que "é pura ilusão nacionalista imaginar que cada língua, independentemente, tenha criado seus cultismos. Normalmente é uma língua quem os cria e as outras os importam ou os modificam por meio de decalque". ${ }^{14}$

Em português, há outra implicação, a formação lexical ou os modelos de formação de palavras possuem origem no grego e no latim. Entretanto, pretende-se distinguir essas construções, por meio da característica que lhe é peculiar, conforme ressaltaram Li Ching (1973), Villalva (1994), Bauer (1998), Amiot e Dal (2007), Petropoulou (2009) e Villalva e Silvestre (2014), entre outras: as vogais, -o- e-i-, intermediárias entre seus constituintes.

É possível identificar ao menos sete tipos de construções diferentes constituídas por elementos neoclássicos:

a) as formadas por dois elementos de origem grega: agrômetro (séc. XIX), ${ }^{15}$ fotógrafo (séc. XIX), ortodoxo (séc. XVII), esquizofasia (séc. XIX), micróbio (1885);

b) as que apresentam dois elementos de origem latina: apicultura (1871), herbívoro (1844), mamífero (1873), calcífero (1873), nocticolor (XIX);

c) as constituídas pelo primeiro elemento de origem grega e o segundo de origem latina: sociologia (1858), neolatino (1873), psicomotor (s/data), endovenoso (s/data), monocultura (séc. XX);

${ }^{13}$ Segundo Skeat (1887, p. 414), doublet são palavras que apresentam duas formas. Entre as motivações para essa concorrência linguística, de acordo com o autor, estão as diferenças dialetais e empréstimos de palavras que têm a mesma origem de outras já existentes na língua tomadora. Nesta língua, as duas formas, geralmente, não são usadas com o mesmo sentido. (SKEAT, 1887, p. 414).

14 Segundo Viaro (2014, p. 277), decalque é “a denominação neológica inspirada na tradução das partes da palavra ou da expressão original".

${ }^{15}$ A fonte da datação dos exemplos é o Dicionário Etimológico da Língua Portuguesa (CUNHA, 2011). 
d) as constituídas pelo primeiro elemento de origem grega e o segundo de origem vernácula: homoafetivo (s/data), agroambiental (s/ data), telealuno (s/data), telemensagem ( $\mathrm{s} / \mathrm{data})$, ecocidade (s/data);

e) as formadas pelo primeiro elemento de origem latina e o segundo de origem vernácula: pluricampeão (s/data); multinacional (séc. XX), onipresente (1873), semiprecioso (séc. XX);

f) as formadas pelo primeiro elemento de origem vernácula e o segundo de origem grega: cachorródromo (s/data), sambódromo (s/data), cervejólogo (s/data), sexólogo (s/data), impostômetro (s/data); e, por fim,

g) as que apresentam o primeiro elemento de origem vernácula e o segundo de origem latina: pesticida (s/data), inseticida (1881), baraticida (s/data), gaticida (1899), raticida (s/data), floricultura (1899), cafeicultura (séc. XX), bananicultura (séc. XX), cacauicultura (séc. XX).

Segundo Villalva (1994, p. 300), as diferentes combinações entre os elementos morfológicos, aos quais a autora inclui também: radicais neoclássicos adjungidos a empréstimos de outras línguas, "demonstra que a concatenação de radicais é um processo morfológico de formação de compostos, disponível no Português Europeu Contemporâneo."

As construções descritas em a) e b) possuem uma motivação histórica para o uso das vogais -o- e-i-. Em ambos os casos, há um modelo clássico de formação de palavras: os processos e os elementos são de origem grega e latina. Retomando Goodwin (1900), as vogais finais das bases à esquerda das composições gregas sofriam alterações, passando, geralmente, a -o, e essas vogais pertenciam ao primeiro elemento. Da mesma forma, como visto em Allen e Greenough (1903) e Bennett (1913), as vogais finais das bases à esquerda nas composições latinas passavam, normalmente, a -i.

Em c), há um hibridismo ${ }^{16}$ que, segundo os puristas, seria uma má formação, pois seus elementos são de origens diferentes, grego e latim. A presença da vogal -o-, nessa constituição, parece natural, uma vez que o primeiro elemento é de origem grega.

Vale ressaltar que, em português, chama a atenção a significativa quantidade de radicais gregos arrolados pelas gramáticas normativas em comparação com os radicais latinos: Cunha e Cintra (1985) registram 39

\footnotetext{
${ }^{16}$ De acordo com Cunha e Cintra (1985, p. 113), "são palavras híbridas, ou hibridismos, aquelas que se formam de elementos tirados de línguas diferentes."
} 
radicais latinos, entre eles 26 são classificados como primeiro elemento de composição e 13, como segundo elemento de composição, e 109 radicais gregos, sendo 63 usados, preferencialmente, como primeiro elemento de composição e 46, como segundo elemento de composição. Rocha Lima (1972) elenca 50 radicais latinos e 91 radicais gregos, aos quais denomina de co-radicais. Bechara (2000) relaciona 230 radicais gregos e 80 radicais latinos. Rocha Lima (1972) e Bechara (2000) não distinguem o posicionamento desses elementos na composição.

A organização feita por Cunha e Cintra (1985, p. 110) deixa evidente que dos 63 radicais gregos que funcionam, preferencialmente, como primeiro elemento da composição, 51 terminam em -o, os outros 12 apresentam terminações em -i, -a e -n. Rocha Lima (1972) e Bechara (2000) expõem variadas terminações dos radicais, mas não explicam as motivações daquelas e quais as formas que são utilizadas nas composições.

Outras análises ratificam a predominância dessa vogal. Tavares da Silva (2013) registra eletro- como encurtamento das palavras eletricidade e elétrico. Essa é a forma encontrada nas recomposições (eletrochoque, eletrocondutor), embora ela não seja escaneada a partir das palavrasfontes, elétrico e eletricidade. Belchor (2009) assinala características do truncamento que validam a descrição dos dados: a) a margem esquerda é preservada na forma truncada; e b) à forma encurtada, uma vogal pode ser adicionada. Duas motivações podem ser inferidas para esse comportamento: o recorte é feito sobre uma unidade morfêmica que tem origem grega e a frequência de uso dos radicais gregos, considerando as listas registradas pelas gramáticas. Isso influenciaria a escolha da vogal -o- para adjungir-se à forma encurtada. $\mathrm{O}$ mesmo não ocorre em alguns truncamentos não morfêmicos, a exemplo de japa, de japonês ou de japonesa; e portuga, de português.

Em d), os primeiros constituintes são de origem grega e sofrem truncamento. No primeiro caso, há uma recomposição, pois homo-, em homoafetivo, assume o sentido de homossexual e não de igual. No segundo caso, no entanto, há uma incoerência entre a palavra-matriz e a forma encurtada, pois agro-, em agroambiental, retoma produção agrícola e não uma palavra da qual o formativo faça parte.

Todavia, algumas formações semelhantes a agroambiental, em "d", trazem uma complexidade para além da correspondência entre forma truncada e a forma plena da palavra, pois agro-, nessas 
construções, pode instanciar diferentes significados: ciência, produto, cultivo, por isso interpretamos o comportamento de agro-como secretion morfoperfilado, ${ }^{17}$ uma vez que o processo abrange uma rede maior de significações, para além de agricultura.

Sobre as construções em f), mais especificamente, sobre -logo, Rondinini (2004, p. 44) afirma que a criação de palavras em série levou "à mudança no status morfológico desses constituintes no século XX", pois adjungem-se a bases livres, e -logo passa de radical a afixo, -ólogo. A vogal, por analogia às formações neoclássicas, realiza-se, mas não pertence ao primeiro elemento e sim ao sufixo, como em cervejólogo. Pires (2014) posiciona-se de maneira semelhante, em relação a -dromo e defende que nas formações mais recentes o outrora radical grego funciona hoje como um sufixo produtivo, -ódromo, como em cachorródromo. $\mathrm{O}$ posicionamento dos autores remete às possibilidades apresentadas por Kastovsky (2009) para interpretação da vogal.

As formações em g) necessitam de uma pesquisa mais acurada, para que sejam feitas afirmações mais precisas; contudo, numa primeira análise, tomando por base os números indicados por Cunha e Cintra (1985) sobre os radicais gregos e latinos, percebe-se que i) há um número menor de palavras constituídas de elementos latinos na segunda posição, ii) as palavras criadas são mais opacas, como em franguívoro, mulherívoro (exemplos de Gonçalves, 2011b), portanto, iii) não geram produção em série e iv) algumas, ainda que se combinem com formas livres, têm contexto de uso específico, retomando as formações neoclássicas prototípicas, tais como pesticida, inseticida e as formações X-cultura, como cafeicultura, bananicultura, cacauicultura.

Embora, inicialmente, pareçam ter menor produtividade, ${ }^{18}$ as composições com as formas latinas apresentam um comportamento morfológico parecido com as formações com elementos gregos: o elemento anterior perde sua vogal, e o -i- assume a posição intermediária

\footnotetext{
${ }^{17}$ Segundo Higino da Silva (2017), secretion morfoperfilado é um processo morfológico no qual as unidades linguísticas passam por metonímia formal e semântica, havendo um encurtamento na forma e uma seleção de sentidos no conteúdo, ativando um e desativando os demais significados da forma truncada.

${ }^{18}$ Para Bybee (2010, p. 94-95) a produtividade, isto é, a capacidade de aplicar a estrutura existente a novos enunciados, está diretamente relacionada à frequência type, ou seja, ao número de diferentes construções que instanciam um esquema, quanto mais alta a frequência type, maior a produtividade.
} 
entre as bases; a presença da vogal ratifica uma composição por analogia. A seleção linguística, -cida e -cultura, associada à função pragmática do termo (utilizadas em palavras que nomeiam produtos da indústria química e para aquelas que nomeiam diferentes produções da agricultura, respectivamente) podem ser gatilhos para o uso do modelo neoclássico de composição.

Palavras compostas, tais como médico-hospitalar; públicoprivado; clínico-cirúrgico, denominadas por Villalva (1994) de compostos sintáticos ${ }^{19}$ e observadas por Gonçalves (2011b), chamam a atenção, pois são processos composicionais não constituídos por elementos neoclássicos em que a vogal -o- se instancia. Porém, como já afirmado anteriormente, as bases à esquerda são formas livres que possuem o -o na sua constituição, o que pode comprometer a análise, embora a manutenção da vogal sobreponha-se à concordância entre os componentes coordenativos.

Há exemplos em que as duas bases fazem parte do vernáculo, como dento-bucal, buco-maxilar, linguodental, e ocorre a instanciação da vogal -o-, porém essa não pertence nem ao primeiro, nem ao segundo elemento, mas caracteriza estruturalmente esses adjetivos compostos, mais do que nas formações com -cida e -cultura, a função pragmática pode ser um fator relevante para escolha do modelo neoclássico para criação dessas palavras.

Os dados apresentados nesta seção, tendo em vista as combinações entre dois elementos neoclássicos ou entre um elemento neoclássico e uma forma livre do vernáculo, podem ser divididos em três grupos, de acordo com as propostas de Bauer (1998) e Kastovsky (2009) para relações das vogais com as bases: a) -o- ou -i- pertencente ao primeiro elemento - agrômetro, agroambiental, neolatino, fotógrafo, pluricampeão, agricultura, apicultura, sociologia, herbívoro, homoafetivo; b) -opertencente ao segundo elemento, comportando-se como parte do sufixo - cachorródromo, cervejólogo (cf. RONDININI, 2004; PIRES, 2014); e c) -i- intermediário não pertencendo a nenhuma das bases baraticida, bananicultura. A gama de combinações possíveis entre os elementos neoclássicos e os do vernáculo gera mudanças nas construções neoclássicas, ocasionando variações no comportamento dos segmentos

19 “Compostos sintácticos são estruturas formadas por um mínimo duas variáveis [...], palavras que integram expressões sintácticas.” (VILLALVA, 1994, p. 329) 
fronteiriços; portanto, enquadrá-los sob uma classificação parece-nos equivocado. Descartamos apenas as possibilidades de interpretá-los como infixo, pois não são morfemas, e como vogal de ligação, uma vez que, diferentemente das vogais de ligação, esse segmento pode portar acento.

Observamos uma ocorrência sistemática desses segmentos nas construções, com predominância da vogal -o-, dado sua maior abrangência na língua: a) maior número de radicais terminados em -o; b) inexistência de formas neoclássicas truncadas com -i; c) uso de -o- como vogal fronteiriça em compostos adjetivos copulativos (coordenados); e d) aproveitamento dessa vogal em casos de recomposição, nos quais a palavra-fonte não apresenta tal segmento, como no caso de "eletro" (TAVARES DA SILVA, 2013).

Embora não tenhamos o compromisso em categorizar as vogais, defendemos a hipótese de que as vogais, -i- e -o-, fronteiriças funcionem como elo entre as construções neoclássicas. Por meio de uma rede de associações (BYBEE, 2010, p. 22-23) entre as palavras, ou seja, por meio de um mapeamento, identificam-se semelhanças semânticas e fonéticas compartilhadas por palavras distintas, chegando assim aos constituintes da construção. Por isso, nomeamos esse segmento, independentemente das relações com as bases, de marcador de construções neoclássicas, semanticamente vazio, alternando entre -o- e -i-, sem levar em conta a pauta acentual. Palavras como buco-maxilar, linguodental, ratificam a hipótese, pois não apresentam uma motivação morfológica para presença da vogal entre as bases.

Considerando o exposto por Bybee (cf. subseção 1.1), a analogia de ordem diacrônica seria a motivação para a semelhança entre as construções analisadas, já que o esquema abstraído dos compostos neoclássicos é o herdado das línguas clássicas, justificando a existência de formações de cunho técnico como agrografia (1871), agrologia (1858).

Segundo Rio-Torto (2014, p. 48), "se a estrutura da palavra não está dissociada das condições genéticas e históricas da sua criação, os vestígios que a história deixa na estrutura da palavra hão de refletir-se no modo como esta está representada no nosso léxico mental."

Gentner e Markman (1997, p. 48) ressaltam que analogia ocorre quando as comparações exibem um elevado grau de semelhança relacional com pouquíssima semelhança de atributo. À medida que a quantidade de atributos similares aumenta, a comparação desloca-se em 
direção à semelhança literal. ${ }^{20}$ Por isso, Bybee (2010, p. 102) pontua que a analogia requer muito conhecimento relacional ou alinhamento estrutural.

Bybee $(2010$, p. 60) afirma que a aceitabilidade de novas formas está pautada na similaridade de sequências frequentes e convencionalizadas. Embora sejam consensuais as afirmações sobre a capacidade criativa da linguagem humana, a autora argumenta que os enunciados são formados por muitas sequências de palavras préembaladas. Esse esquema é fruto das repetições realizadas na fala, que, segundo Bybee (2010), necessita de uma ou duas ocorrências para estabelecer-se. A criatividade, nesse modelo, estaria justamente na forte relação entre esquemas pré-fabricados e o surgimento de novas palavras por meio deles. Portanto, nas formações neoclássicas, o marcador composicional seria a sequência previsível e âncora para novas formações que instanciam o ESQUEMA DE FORMAÇÃO DE PALAVRAS NEOCLÁSSICAS. De acordo com nossa hipótese, esse seria acionado pela moldura comunicativa, ${ }^{21}$ o evento de uso específico: técnico-científico. O marcador composicional seria a contraparte formal, na qual o falante se ancoraria para criar novas palavras.

As análises sugerem três tipos de construções que instanciam o ESQUEMA DE FORMAÇÃO DE PALAVRAS NEOCLÁSSICAS: a) construções neoclássicas prototípicas, como em agrografia (1871), agricultura (séc. XV), agrícola (1635), agrimensura (1784) b) construções neoclássicas híbridas, a exemplo de agronegócio, agroportal, agroreformista, baraticida, monocultura, sociologia; e c) construções vernaculares com marcador composicional, tal como dento-bucal, bucomaxilar, linguodental.

Portanto, as construções prototípicas são elementos centrais que irradiam efeitos de prototipicidade, a exemplo das já citadas agrômeno, agromania, agrografia, agrologia. Essas construções são modelos para outras, atraindo exemplares em função de suas semelhanças, tais como: (a) construções neoclássicas híbridas - que se desmembram entre as

\footnotetext{
${ }^{20}$ Analogy occurs when comparisons exhibit a high degree of relational similarity with very little attribute similarity. As the amount of attribute similarity increases, the comparison shifts toward literal similarity. (GENTNER; MARKMAN, 1997, p. 48). 21 "As molduras comunicativas constituem estruturas de conhecimento relacionadas a formas organizadas de interação. Caracteriza-se por um conjunto de procedimentos que identifica um tipo de atividade social". (MARTELOTTA; PALOMANES, 2008, p. 185).
} 
que são constituídas por elementos neoclássicos, latinos e gregos, independente da ordem que assumam na construção, e as constituídas por elementos clássicos e do vernáculo e vice-versa, com a presença de marcador composicional; e (b) construções vernaculares com marcador composicional - aquelas em que as bases à direita e à esquerda são elementos do vernáculo; entretanto, apresentam a vogal -o- fronteiriça, acionada pela moldura comunicativa, retomando a rede analógica, proposta por Bybee (2010). Isso nos leva a sugerir um continuum de construções e processos:

FIGURA 1 - Continuum das construções neoclássicas

\begin{tabular}{|cccc|}
\hline $\begin{array}{c}\text { Construções vernaculares } \\
\text { com marcador }\end{array}$ & $\begin{array}{c}\text { Construções } \\
\text { neoclássicas } \\
\text { híbridas }\end{array} ~ \gg \gg$ neoclássicas prototípicas \\
\hline
\end{tabular}

FIGURA 2 - Detalhamento dos processos de formação de palavras neoclássicas

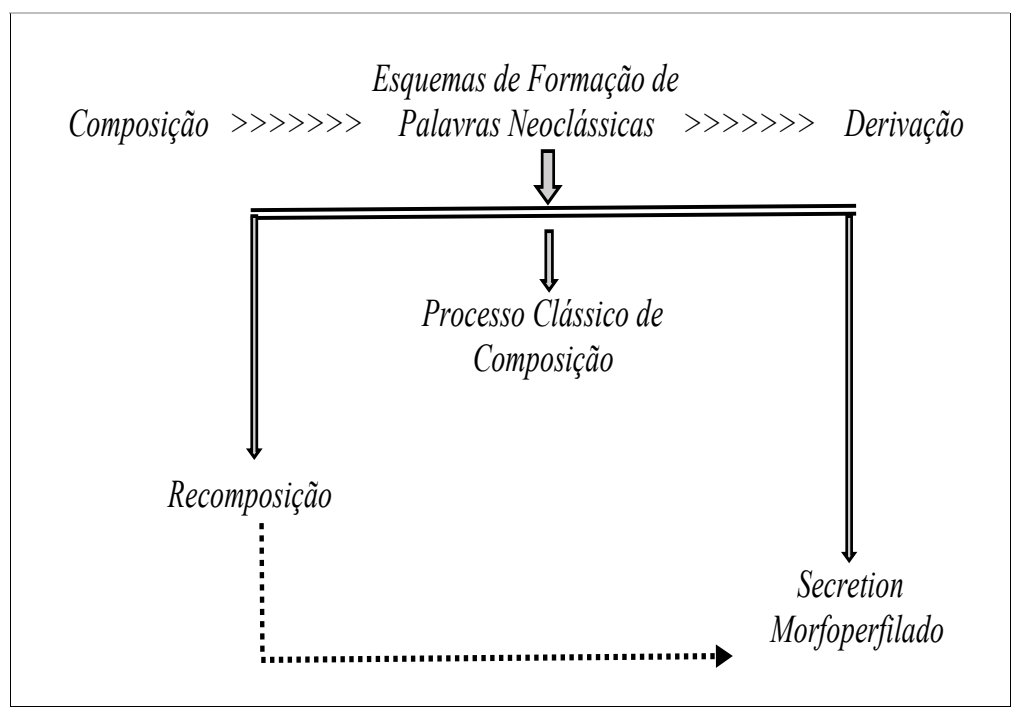


O esquema de formação das construções tratadas na figura anterior participa do continuum composição-derivação, ratificando a maleabilidade das fronteiras entre os processos de formação de palavras complexas, como detalhado na figura 3 a seguir:

FIGURA 3 - Desmembramento do processo clássico de composição

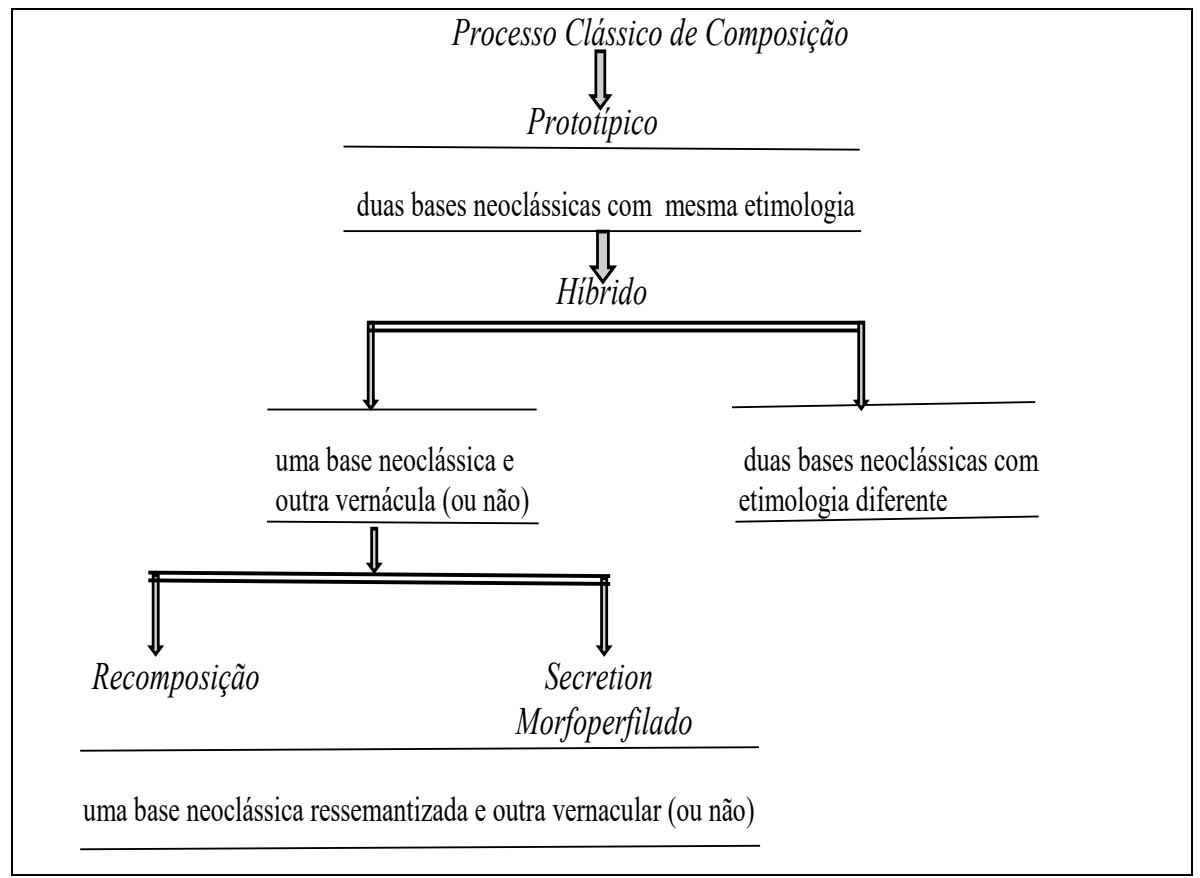

Tendo em vista a descrição apresentada nesta pesquisa, os compostos neoclássicos encontram-se entre a composição e a derivação, uma vez que reúnem características dos dois processos. Contudo, considerando as peculiaridades das diferentes construções congregadas pelo rótulo de "compostos neoclássicos", é possível estabelecer uma representação exemplar ou um esquema, ao qual nomeamos de ESQUEMA DE FORMAÇÃO DE PALAVRAS NEOCLÁSSICAS (EFPN), que, sendo menos detalhado que os exemplares, abarca uma diversidade de construções e serve como âncora para novas formações. Esse esquema é instanciado pelas construções neoclássicas prototípicas, 
formadas por dois elementos neoclássicos de mesma origem (agrômeno, agromania, agrografia, agrologia, homófono, biófito); construções neoclássicas híbridas, formadas por elementos neoclássicos de origens distintas (automóvel, decímetro, sociologia); construções híbridas constituídas por elementos neoclássicos e elementos do vernáculo (agrobanditismo, agroaçucareiro, agroalimentar, telemensagem, heteroagressão, ecoturismo) ou não (eletrobike, petrodiesel, agroboy, agrogirl, agroshop); e construções vernaculares, formadas por elementos nativos, com marcador composicional (médico-dentário, luso-brasileiro, sócio-econômica, linguodental, bucomaxilar).

As construções neoclássicas prototípicas e híbridas, constituídas por elementos neoclássicos, seriam formadas pelo processo clássico de composição; as construções neoclássicas híbridas, constituídas por elemento neoclássico e elemento do vernáculo, mais periféricas, seriam criadas via recomposição ou secretion morfoperfilado. As construções vernaculares com marcador composicional, apesar de serem instanciações do EFPN, compartilham mais características com a composição.

\section{Conclusão}

Neste trabalho, analisamos diferentes construções tradicionalmente denominadas compostos neoclássicos, e identificamos, fundamentados no modelo proposto por Bybee (2010), uma rede associativa entre elas, conectada por um segmento vocálico fronteiriço presente entre as bases das construções constituídas por formativos neoclássicos, -o- ou -i-. A realização dessas vogais está diretamente relacionada à origem desses elementos, se grega ou latina. Notamos que algumas construções constituídas apenas por elementos do vernáculo também apresentam -ocomo vogal final da primeira base, por motivação morfológica, como em médico-cirúrgico, ou não, como em dento-bucal. Inferimos que a moldura comunicativa tenha acionado a vogal, e que a escolha do -o- faz-se pela frequência de uso, tendo em vista, segundo as gramáticas normativas, um maior número de radicais gregos na língua e, consequentemente, uma maior ocorrência do -o-.

Considerando essa descrição, classificamos a vogal fronteiriça de marcador composicional, específico de processos de formação de palavras que possuem elementos neoclássicos ou que possuem uma função pragmática típica dessas construções, isto é, são designações 
técnicas ou científicas, apesar de os elementos serem do vernáculo. Por isso, propusemos o continuum de construções: Construções neoclássicas prototípicas $>$ Construções neoclássicas híbridas $>$ Construções vernaculares, todas com marcador composicional. As construções instanciam o esquema geral, aqui denominado ESQUEMA DE FORMAÇÃO DE PALAVRAS NEOCLÁSSICAS que serve como fonte para criação de novas palavras.

\section{Agradecimentos}

Agradecemos ao Vinicius Francisco Chichurra pela tradução dos termos em grego clássico que constituem a seção 2.2 Gramática grega, à Katia Emmerick Andrade e ao Roberto Rondinini pelas valiosas contribuições para este trabalho.

\section{Referências bibliográficas}

ALLEN, Joseph Henry; GREENOUGH, James Bradstreet. New latin grammar. Boston: Ginn, 1903.

AMIOT, Dany; DAL, Georgette. Integrating neoclassical combinig forms into a lexeme-based morphology. In: BOOIJ, Geert et al. (Org.). MEDITERRANEAN MORPHOLOGY MEETING, FIFTH, 2007, Fréjus, University of Bologna. Proceedings... Fréjus, University of Bologna, 2007. Disponível em: <http://www.lilec-mmm.it/wp-content/ uploads/2012/09/232-336-Amiot-Dal.pdf>. Acesso em: 28 set. 2014.

BAUER, Laurie. Is there a class of neoclassical compounds, and if so is it productive? Linguistics, Boston, v. 36, n. 3, p. 403-422, 1998.

BAUER, Laurie. The Borderline between derivation and compounding. In: DRESSLER, W. et al. Morphology and its demarcations. Amsterdam; Philadelphia: John Benjamins Publishing Company, 2005.

BELCHOR, Ana Paula Victoriano. Construções de truncamento no português do Brasil: análise estrutural à luz da teoria da otimalidade. 2009. 151f. Dissertação (Mestrado em Letras Vernáculas) -, Universidade Federal do Rio de Janeiro, 2009.

BECHARA, Evanildo. Moderna gramática portuguesa. Rio de Janeiro: Lucerna, 2000. 
BENNETT, Charles Edwin. A latin grammar. Massachusetts: Nowood Press, 1913.

BISOL, Leda. O clítico e seu status prosódico. Revista de Estudos da Linguagem, Belo Horizonte, v. 9, n.1, p. 5-30, 2000.

BOOIJ, Geert. Compounding and derivation. evidence for construction morphology. In: DRESSLER, Wolfgang et al. Morphology and its demarcations. Amsterdam/Philadelphia: John Benjamins Publishing Company, 2005.

BYBEE, Joan. Language, usage and cognition. New York: Cambridge Universety Press, 2010.

CAETANO, Maria do Céu. A meio caminho entre derivação e a composição. Estudos Linguísticos/Linguistic Studies, Lisboa, v. 5, p. 131-140, 2010.

CALLOU, Dinah; SERRA, Carolina. Variação do rótico e estrutura prosódica. Revista do GELNE, São Paulo, v. 14, n. especial, 2012.

CROFT, William; CRUSE, Allan D. Cognitive linguistics. Cambridge: University of Cambridge Press, 2004.

CUNHA, Antonio Geraldo da. Dicionário etimológico da língua portuguesa. Rio de Janeiro: Nova Fronteira, 2011.

CUNHA, Celso; CINTRA, Lindley. Nova gramática do português contemporâneo. Rio de Janeiro: Nova Fronteira, 1985.

FERREIRA, Aurélio Buarque de Holanda. Novo dicionário eletrônico Aurélio da língua portuguesa. Curitiba: Positivo, 2009. CD-ROM. Versão 6.0 .

FERREIRA, Rosangela Gomes. Uma abordagem morfossemântica das formações tele-x no português brasileiro. In: JEL - JORNADAS DE ESTUDOS DA LINGUAGEM, VI, 2010, Rio de Janeiro. Programação e Resumos... Rio de Janeiro: UERJ, 2010.

GENTNER, Dedre; MARKMAN, Arthur B. Structure mapping in analogy and similarity. American Psychologist, Washington, DC., v. 52, n.1, p. 45-56, 1997.

GONÇALVES, Carlos Alexandre. Composição e derivação: polos prototípicos de um continuum? Pequeno estudo de casos. Domínios da Linguagem, Uberlândia, v 5, n. 2, p. 60-90, 2011 a. 
GONÇALVES, Carlos Alexandre. Compostos neoclássicos: estrutura e formação. ReVel, edição especial, n. 5, p. 6-39, 2011b. Disponível em: $<$ http://www.revel.inf.br/files/artigos/revel_esp_5_compostos.pdf $>$. Acesso em: 9 mar. 2013.

GONÇALVES, Carlos Alexandre; ANDRADE, Katia Emmerick. E1 status de los componentes morfológicos y el continuum composiciónderivación en portugués. Linguística, La Rioja, Argentina, v. 28, n. 2, p. 119-145, 2012.

GOODWIN, Willian Watson. Greek grammar. Boston: Ginn, 1900.

GRANDE Dicionário Houaiss beta da língua portuguesa. Disponível em: <http://houaiss.uol.com.br>. Acesso em: 14 abr. 2016.

HIGINO da SILVA, N. A diversidade tipológica na composição de palavras neoclássicas agro- $X$. Revista Fórum Linguísticos, Florianópolis, 2017. [no prelo]

HORTA, Guida Nedda Barata Parreiras. Os gregos e seu idioma. Rio de Janeiro: Livraria Acadêmica, 1970. v 1.

HOUAISS, Antônio et al. Dicionário eletrônico Houaiss de língua portuguesa. Rio de Janeiro: Instituto Antônio Houaiss, 2009. CD-ROM. Versão 3.0.

KASTOVSKY, Dieter. Astronaut, astrology, astrophysics: about combining forms, classical compounds and affixoids. In: SYMPOSIUM ON NEW APPROACHES IN ENGLISH HISTORICAL LEXIS, 2008, Lammi, Finland. Selected proceedings... Somerville, MA, 2009.

KEHDI, Valter. O problema do infixo em português. Filologia e Linguística Portuguesa, São Paulo, n. 3, p. 191-196, 1999.

LANGACKER, Ronald Wayne. Foundations of cognitive grammar: theoretical prerequisites. California: Stanford University Press, 1987. v. 1.

LANGACKER, Ronald Wayne. Congnitive Grammar: a basic introduction. New York: Oxford University Press, 2008. https://doi. org/10.1093/acprof:oso/9780195331967.001.0001

LI CHING. Sobre a formação de palavras com prefixos em português actual. Boletim de Filologia, Lisboa, v. XXII, p. 3-100, 1973. 
LÜDELING, Ankle. Neoclassical word-formation. In: BROWN, Keith. Encyclopedia of Language and Linguistics. Orford: Elsevier, 2006.

MACHADO, José Pedro. Dicionário onomástico etimológico da língua portuguesa. Lisboa: Conferência Editorial, 1984. v. 1.

MARTELOTTA, Mario Eduardo; PALOMANES, Roza. Linguística cognitiva. In: MARTELOTA, Mario Eduardo et al. Manual de Linguística. São Paulo: Contexto, 2008.

MATTOSO CAMARA, Joaquim Junior. Dicionário de linguística e gramática: referente à língua portuguesa. Petrópolis: Vozes, 1977.

MONTEIL, Pierre. Elementos de fonética y morfologia del latín. Tradução de Concepción Fernández Martínez. Sevilla: Universidad de Sevilla, 1992.

MONTEIRO, José Lemos. Morfologia portuguesa. Fortaleza: EDUFC, 1986.

MONTEIRO, José Lemos. Quem disse que não há infixos em português? In: CONGRESSO NACIONAL DE LINGUÍSTICA E FILOLOGIA, II, 1998, Rio de Janeiro. Anais... Rio de Janeiro: UFRJ, 1998.

NASCENTES, Antenor. Dicionário etimológico resumido. Rio de Janeiro: INL, 1966.

NESPOR, Marina; VOGEL, Irene. Prosodic phonology. DordrechtHolland: Foris Publications, 1986.

PANOCOVÁ, Renáta. Morphological properties of neoclassical formations in English. Bulletin of the Transilvania University of Brasov, series IV. Philology, Cultural Studies, România, v. 5, n. 54, p. 31-36, 2012.

PETROPOULOU, Evanthia. On the parallel between neoclassical compounds in English and Modern Greek. Patras Working Papers in Linguistics, Bloomington, v. 1, p. 40-58, 2009.

PIRES, José Augusto de Oliveira. O estatuto morfológico do formativodromo no português brasileiro. 2014. Dissertação (Mestrado em Língua Portuguesa) - Universidade Federal do Rio de Janeiro, Rio de Janeiro, 2014.

RALLI, Angela. Greek deverbal compounds with bound stems. Journal of Southern Linguistics, v. 29, n. 1-2, p. 150-173, 2008 a. 
RALLI, Angela. Compound markers and parametric variation. STUFSprachtypologie und Universalienforschung, v. 61, n. 1, p. 19-38, $2008 \mathrm{~b}$. RIO-TORTO, Graça Maria. Desafios em morfologia história e (re) conhecimento. In: VIARO, Mario Eduardo. Morfologia Histórica. São Paulo: Cortez, 2014.

ROCHA LIMA, Carlos Henrique da. Gramática normativa da língua portuguesa. Rio de Janeiro: José Olympio, 1972.

RONDININI, Roberto Botelho. Formações $x$-ólogo e $x$-ógrafo no português: uma abordagem derivacional. 2004. 113f. Dissertação (Mestrado em Letras Vernáculas) - Universidade Federal do Rio de Janeiro, Rio de Janeiro, 2004.

RONDININI, Roberto Botelho; GONÇALVES, Carlos Alexandre. Formações X-logo e X-grafo: um caso de deslocamento da composição para a derivação? In: ENCONTRO NACIONAL DA ASSOCIAÇÃ̃O PORTUGUESA DE LINGÜÍSTICA(APL), XXII, 2007, Coimbra. Textos selecionados... Lisboa: Colibri, 2006. v. 22.

SKEAT, W. W. Principles of english etymology: the native element. Orfoxd: Clarendon Press, 1887.

TAVARES DA SILVA, João. O estatuto morfológico do formativo eletroem português. 2013. 129f. Dissertação (Mestrado) - Universidade Federal do Rio de Janeiro, 2013.

VIARO, Mario Eduardo. Etimologia. São Paulo: Contexto, 2014.

VILLALVA, Alina. Estruturas morfológicas: unidades e hierarquias nas palavras do português. 1994. Lisboa: [s.n.], 1994. Disponível em: $<$ http://www.uam.es/gruposinv/upstairs/upstairs2/curricula/trabajos/ villalva_1995_estructuras.pdf>. Acesso em: 17 jul. 2016.

VILLALVA, Alina; SILVESTRE, João Paulo. Introdução ao estudo do léxico: descrição e análise do português. Rio de Janeiro: Vozes, 2014.

WARREN, Beatrice. The Importance of combining Forms. In: DRESSLER, Wolfgang. U. et al. Contemporary morphology. Berlin; New York: Mouton de Gruyter, 1990. 